\title{
Provincial and Outdated?
}

KARL OTTO ELLEFSEN

Oslo School of Architecture and Design 
Teachers are far more decisive for the quality of architectural education than curriculum, academic organization and management. Put all efforts into reorganization and restructuring. It will, however mean little to the quality of education. Good schools are built by outstanding teachers. And architectural education is socially relevant and valid, linking to the culture and needs of a society. At least this was so in a small school close to the North Pole, started in 1945, right after the second World War as part of a process of rebuilding a nation. At the beginning education and practice merged entirely, teachers taught trough their projects, students won competitions for substantial public commissions before they graduated. After a while the Oslo school was molded into a tradition, a little national romantic from the start, cherishing the thousandyear-old wooden way of building, and indulging into the Norwegian landscapes filled with local character of place. So far to the north that characteristics like 'ahead of the game' or 'mainstream' had little meaning. New concepts and ways had to travel far and took time.

In a country where pragmatic needs set the agenda, the school established a corrective, defending architecture as works of art, as 'unicas' - one of a kind - educating master builders who knew the terrain, with a sense of place, in a material tradition of wood, stone, brick and concrete, working with experimental tectonics. Four generation of teachers, the last three educated in the school. A small academy, entirely studio based.

What happens to a school like this when education is an international commodity and teachers are recruited globally? Bringing in their own luggage and agendas and asking, 'Why not do something else?' The school does not fall apart. Modern management keeps it running smoothly. In terms of educational institutions, a good reputation seems to sustain. Elaborated strategies define potential new roles for the school in the world. Does culture beat strategy, is there a ghost in the machine that cannot be removed? Or is the school transforming into something found anywhere in the world, and mostly mediocre?

A few years ago, a known figure in the EAAE system stated that: 'There is no such thing as a global curriculum in architecture', believing that schools gave priority to and took care of their own identities. Was this a false statement? 